CUADERNOS DE ESTUDIOS GALLEGOS, LXIV Núm. 130 (enero-diciembre 2017), págs. 141-166

ISSN: $0210-847 \mathrm{X}$

DOI: $10.3989 /$ ceg.2017.130.05

\title{
DEL BURGO DE PINO A LA VILLA DE MONFORTE EN LA TIERRA DE LEMOS (SIGLOS XII-XIII)
}

\author{
Luis Manuel IbáÑez Beltrán \\ Universidad de Santiago de Compostela \\ ORCID iD: http://orcid.org/0000-0003-4846-6144
}

Copyright: (C) 2017 CSIC. Este es un artículo de acceso abierto distribuido bajo los términos de una licencia de uso y distribución Creative Commons Attribution (CC-by) España 3.0.

Cómo citar/Citation: Luis Manuel IbÁÑez Beltrán, "Del burgo de Pino a la villa de Monforte en la tierra de Lemos (siglos XII-XIII)", Cuadernos de Estudios Gallegos, 64, núm. 130 (2017), págs. 141-166, DOI: http://dx.doi.org/10.3989/ceg.2017.130.05 


\section{DEL BURGO DE PINO A LA VILLA DE MONFORTE EN LA TIERRA DE LEMOS (SIGLOS XII-XIII)}

RESUMEN

La Tierra de Lemos, en el sur de la provincia de Lugo, protagoniza una larga evolución desde los Lemavos prerromanos, en la que se ha ido adaptando a las diferentes realidades y episodios históricos. Dentro de este desarrollo, los siglos de la Plena Edad Media marcan un punto de inflexión: la fundación del burgo de Pino, después villa de Monforte, su nueva cabecera comarcal. Con este nuevo referente urbano, una tierra marcadamente rural y agraria recibe una nueva realidad morfológica, económica y social. Paralelamente, el conjunto de Lemos conoce un nuevo agente de poder: el concejo monfortino. Éste viene a unirse a los otros dos poderes locales: el monasterio benedictino de San Vicente del Pino y la nobleza laica, la de los condes en / de Lemos, llamados a ser la más importante casa nobiliar gallega de la Baja Edad Media. Los tres poderes juntos, en continua pugna, marcan la estructura y dinámica de la nueva villa, sobre la cual la corona ejercerce un cierto rol de balanza, inclinandola hacia un lado u otro con sus concesiones y prebendas.

Palabras clave: burgo de Pino, villa de Monforte, monasterio de San Vicente del Pino, concejo, condes de Lemos

\section{DO BURGO DE PINO Á VILA DE MONFORTE NA TERRA DE LEMOS} (SÉCULOS XII-XIII)

RESUMO

A Terra de Lemos, no sur da provincia de Lugo, protagoniza unha longa evolución dende os lemavos prerromanos, na que tense ido adaptando ás diferentes realidades e episodios históricos. Dentro deste desenrolo, os séculos da Plena Idade Media marcan un punto de inflexión: a fundación do burgo de Pino, despois vila de Monforte, a súa nova cabeceira comarcal. Con este novo referente urbán, unha terra marcadamente rural e agraria recibe unha nova realidade morfolóxica, económica e social. Paralelamente, o conxunto de Lemos coñece un novo axente de poder: o concello monfortino. Éste ven unirse ós outros dous poderes locais: o mosteiro bieito de San Vicente do Pino e a nobreza laica, a dos condes en / de Lemos, chamados a ser a máis importante das casas nobiliares galegas da Baixa Idade Media. Os tres poderes xuntos, en continua pugna, marcan a estructura e dinámica da nova vila, sobre a cal a coroa exerce un certo rol de balanza, inclinandoa cara un lado ou outro coas súas concesións e prebendas.

Palabras clave: burgo de Pino, vila de Monforte, mosteiro de San Vicente do Pino, concello, condes de Lemos.

\section{FROM THE BURGH OF PINO TO THE TOWN OF MONFORTE IN THE LAND OF LEMOS $\left(12^{\text {th }}-13^{\text {th }}\right.$ CENTURIES $)$}

AbSTRACT

The land of Lemos, in the south of the province of Lugo, has undergone a long process of evolution, from the pre-Roman culture of Lemavos to today's world. In this evolution the land of Lemos has adapted to different realities and historic moments. The High Middle Ages represent a particularly important time during this period, bearing witness to the foundation of the burg of Pino and then the town of Monforte, the new headquarter of the area. This new urban space sees a land that is markedly rural and agrarian meet a new morphological, economic and social reality. At the same time, Lemos also welcomes a new kind of authority, the council of Monforte. This council then joins with two other local powers, the Benedictine monastery of San Vicente del Pino and the secular nobility of Lemos County, the most important noble family in the Late Middle Ages in Galicia. The three powers together, in constant clashes, define the structure and dynamic of this new town, a town on which the crown exerts a certain kind of power balance, influencing it in one direction or the other with concessions and grants.

Key words: burgh of Pino, town of Monforte, monastery of San Vicente del Pino, council, counts of Lemos. 
Recibido/Received: 06/07/2016

Aceptado/Accepted: 22/05/2017

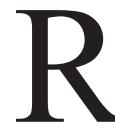

esulta ciertamente difícil imaginar mayor satisfacción para el interesado en la evolución del territorio que la producida al leer, de las plumas de y Ptolomeo, la existencia de un pueblo prerromano de nombre "lemavo", asentado al sur de la ciudad de Lugo, sobre todo, si, aquel, es conocedor de la presente existencia de la comarca de la "Tierra de Lemos", en el sur de la actual provincia lucense. La estabilidad del topónimo nos aporta los extremos de un hilo conductor, el de la tierra de Lemos, estable y cambiante con los siglos, testigo de los diferentes episodios, casi inmutable en el escenario, alterado en todo lo demás ${ }^{1}$.

Extendido el ovillo de nuestro hilo, lo seguiremos unas cuantas centurias para detenernos en una horquilla cronológica que recibe nuestro particular interés en estos momentos: la plena Edad Media. Centrados, pues, en ese momento, podemos atar un nudo trascendental: el conde de Galicia, Raimundo de Borgoña, en colaboración con dos instituciones ya vigentes en el lugar, la nobleza secular representada por Froila Díaz y su esposa, y la espiritual de la comunidad benedictina de San Vicente del Pino, legarán a esta tierra una capitalidad comarcal, distinta, aunque probablemente en el mismo emplazamiento de la citada por el autor clásico. Ese nuevo núcleo, testimonio de la llegada de la europa románica urbana a Lemos, asumirá, con el tiempo, el nombre de Monforte, el monte fuerte, y de Lemos, a la cabeza hasta nuestros días de este territorio. Así pues, en el año 1104 nacía un punto netamente diferente en esta ya anciana madeja. Es el comienzo de este artículo.

Empero, antes de comenzar a tejer las urdimbres apuntadas, responderemos a dos cuestiones básicas: los motivos y el marco cronológico exacto. En primer lugar, la elección de Monforte, si no ha quedado ya suficientemente justificada en el hecho de ser una realidad plenomedieval que enriquece un marco netamente anterior, despliega todo su interés científico por ser la silla de la que será la familia nobiliar más importante de Galicia en la Baja Edad Media e, incluso,

\footnotetext{
1 Germán VÁzquez Sueiro, Historia de Monforte y su tierra de Lemos, Monforte de Lemos, Ed. Evergráficas S.A., 1990, págs. 56-59.
} 
la Edad Moderna, los Condes de Lemos. Ellos pugnarán por el poder, también local, desde la cima del monte de San Vicente, en el que compartirán espacio con el monasterio benedictino y el concejo de la villa.

En segundo lugar, nos hemos referido ya abundantemente a nuestro interés particular en el ámbito cronológico de la Plena Edad Media. La razón de esta elección estriba en las importantes modificaciones que sufre la tierra de Lemos en este momento, dentro de las cuales queremos reivindicar la importancia del nacimiento como burgo, y su conversión en villa, de Monforte, un proceso homologable al conocido para otros lugares de Galicia, en cuya relación no acostumbra a incluirse.

Recortamos, pues, en este instante el pedazo de hilo que nos ocupa, ese horizonte plenomedieval de los siglos XII-XIII. Lo hacemos para realizar un pequeño balance historiográfico para esa horquilla, el cual debe comenzar, necesariamente, por G. Vázquez Sueiro y su obra sobre la historia de Monforte, un libro amplio y ya un tanto superado en su encuadre global, si bien sigue siendo la gran referencia para el conocimiento del devenir histórico local. A él sumaremos tres trabajos más: los Apuntes para la historia de Monforte de Moure-Mariño, relatos inconexos de la historia local; la obra Monforte de Lemos de Hermida Balado, un repaso por los monumentos de la ciudad y su historia; y, mucho más reciente, el artículo de E. Iglesias Almeida Las fortificaciones monfortinas. Si las primeras son los gigantes sobre los que queremos subirnos para aportar nuevas reflexiones en la actualidad, la última es el complemento perfecto para poder hacerlo.

\section{EL TopÓNIMO "PINO"}

Los albores del siglo XII traen aires fundacionales para la cima del monte de San Vicente. Pese a que no conservamos testimonios directos, podemos señalar el año de 1104 como el de la formación de esta puebla, de vocación comarcal y erigida sobre territorio del cenobio benedictino -al que los diferentes monarcas compensarán repetidas veces por las pérdidas consecuentemente ocasionadas-, con la declarada intención de crear así un espacio urbano capaz de acoger ferias y mercados ${ }^{2}$.

Alfonso IX nos ha legado varios documentos en los que menciona a esta puebla o burgo, tal y como se refiere a ella indistintamente, y en los que nos dibuja un núcleo perteneciente en una tercera parte al monasterio de San Vicente desde el mismo momento fundacional, núcleo al que llama Pini ${ }^{3}$.

\footnotetext{
G. VÁzquez Sueiro, Historia de Monforte..., págs. 140-142.

3 Carlos Rodríguez Fernández, La colección diplomática de San Vicente del Pino, tesis doctoral inédita dirigida por J. I. de Viana y Vieites, Granada, Universidad de Granada, Facultad de Filosofía y Letras, 1990, doc. núm. 4, págs. 242-243.
} 
Este término, tan cercano al de "Pino" que completa el nombre de la casa benita monfortina, ha hecho que tradicionalmente fuera sostenida por voces como Moure-Mariño la derivación del apellido del cenobio del nombre original de la puebla ${ }^{4}$. Este extremo, se veía confirmado en el documento más antiguo conservado por el monasterio, el de la prueba caldaria en él realizada en el año 915, que apenas se refería a la iglesia cenobítica como San Vicente ${ }^{5}$.

Sin embargo, y sin desafiar la importancia del testimonio susodicho, también primera referencia a la iglesia de Santa María, nos creemos en condiciones de cuestionar el origen de "Pino" en la puebla homónima. Para justificar tal afirmación, nos remitimos a otra institución asentada en la tierra de Lemos, en concreto en el municipio de Ferreira de Pantón: el monasterio de San Vicente de Pombeiro. El más antiguo de sus documentos conservados, datado en el 935 -apenas veinte años después de nuestra prueba caldaria-, recoge la donación al cenobio de la villa e iglesia de Caneda, en el actual término municipal de Monforte, recogiendo los límites de sus términos, colindantes con otras parroquias monfortinas y, entre ellas, con los de Sancto Vicentio de Pino ${ }^{6}$.

Si este testimonio no fuera suficientemente elocuente, aún podemos esgrimir otro documento ligeramente más tardío, del 1098. Apenas cuatro años antes de la fundación del burgo de Pini, el pequeño monasterio de San Juan de Cirusia, que M.J. Portela Silva identificó como la actual San Salvador de Seoane ${ }^{7}$, era entregado en su cuarta parte al abad de San Julián de Samos. Al describir sus términos, aparece de nuevo Sanctum Vincenti de Pino, junto a otras parroquias actuales monfortinas, si bien en esta ocasión del flanco noroeste (Tor, Moreda, Ribas Altas) $)^{8}$.

Parece, pues, meridianamente claro que el apelativo Pino, por el que se llamó al burgo en sus primeros momentos y que quedó luego inmortalizado en el nombre del monasterio, es claramente anterior al momento de la fundación, y remitiría, más bien, a la parroquia de San Vicente, netamente más antigua que el enclave urbano.

\footnotetext{
4 Luis Moure-Mariño, Apuntes para la historia de Monforte de Lemos, Santiago de Compostela, Xunta de Galicia, 1997, págs. 9-18.

5 C. Rodríguez Fernández, La colección diplomática de San Vicente..., doc. núm. 2, págs. 237-240.

6 Manuel Lucas Álvarez y Pedro Lucas Domínguez, El priorato benedictino de San Vicenzo de Pombeiro y su colección diplomática en la Edad Media, Sada, Ediciós do Castro, 1996 (Galicia Medieval: Fontes, 2. Publicacións do Seminario de Estudos Galegos), doc. núm. 1, págs. 53-54.

7 María José Portela Silva (ed.), Documentos da Catedral de Lugo. Século XIV, Santiago de Compostela, Consello da Cultura Galega. Sección de patrimonio, 2005 (Fontes para a Historia de Galicia, 5), doc. núm. 922, págs. 57-59.

8 Manuel Lucas Álvarez, El tumbo de San Julián de Samos (siglos VIII-XII), Estudio introductorio. Edición diplomática. Apéndices e índices, Santiago de Compostela, Obra social Caixa Galicia, 1986, doc. 19 , págs. 471-472.
} 
Tanto por la presencia de San Vicente del Pino, como por la repetición en su posición geográfica aproximada, de los topónimos de parroquias bien conocidas (y que, en muchos casos, formarán parte del arcedianato de Lemos, encabezado por el abad), podríamos afirmar que, al menos, el precedente a la malla parroquial, casi inmutable desde la Plena y Baja Edad Media, estaría ya consolidado antes del periodo que nos ocupa.

\section{El BURGo DE PINO}

El topónimo Pino precede a la fundación del burgo, al cual hemos sustraído su paternidad. Y con ella establecemos que había, al menos, un precedente de la malla parroquial y San Vicente del Pino formaba parte de él. Con la fundación de 1104 se pretende un enclave diferente a ese precedente. Lo primero que la plena Edad Media, que la Europa románica cede a Lemos es precisamente eso, algo totalmente diferente -y urbano- con respecto a lo anterior, plenamemente rural. Pini podrá heredar el nombre de una realidad previa, pero, como burgo, viene a denominar a un ente diferenciado destinado a acoger a una población con actividades económicas nuevas. No precisamos testimonio más elocuente que la voluntad fundacional de acoger ferias y mercados para defender que los habitantes llamados a integrar el nuevo núcleo no serán meros agricultores y ganaderos, los cuales ya 'poseían' la inmensidad de la tierra de Lemos y el marco previo que ya hemos referido. El burgo viene a dar respuesta a una necesidad, la de un espacio diferente del que se beneficiarán todos los agentes previos a través de sus tributos, tanto por las actividades particulares a desarrollar en él, como por el movimiento de personas y mercancías hacia el nuevo punto de referencia (la corona acabará por beneficiar a la casa benedictina con los portazgos de la villa, ya veremos cuando y en qué contexto).

En este sentido, la aparición de un burgo en Lemos es sinónimo de la llegada a este lugar de una realidad que se estaba asentando en Galicia, con fundaciones homónimas en lugares tales como Padrón o Noia ${ }^{9}$, y siguiendo una estela abierta ya en el siglo XI por Santiago, la villa burgensis ${ }^{10}$, adaptación local de un sustantivo extraño que aparecía por primera vez en territorios hispánicos en el fuero de Jaca $^{11}$. Como en todos esos casos, un burgo supondrá una realidad socioeconómica diferente y, consecuentemente, una estructura social distinta, con presencia de mercaderes y artesanos, cuya vitalidad y necesidad últimas se prueban, más allá de cualquier testimonio documental, en la propia supervivencia del núcleo.

\footnotetext{
9 Fernando López Alsina, "La repoblación humana costera del norte peninsular", en Los fueros de Ávilés y su época, Oviedo, Real Instituto de Estudios Asturianos, 2012, págs. 174-204.

${ }^{10}$ Fernando López Alsina, La ciudad de Santiago de Compostela en la Alta Edad Media, $2^{\mathrm{a}}$ ed. corregida, Santiago de Compostela, Consorcio de Santiago, Universidade de Santiago de Compostela, 2013, pág. 274.
} 
El documento fundacional, hoy perdido, pero al que tenemos acceso por estar recogido parcialmente en La España Sagrada ${ }^{12}$, así como por hallarnos en posesión de una copia-traducción de la misma, procedente de manos privadas ${ }^{13}$, insiste en esas particularidades económicas arengando a los nuevos pobladores -todo aquel que así lo desease- a vender allí sus productos, además de promover ferias y mercados. Testimonia, además, una idea ampliamente recogida por G. Vázquez Sueiro, la necesaria sintonía entre el monasterio benedictino y el conde en Lemos don Froila Díaz ${ }^{14}$, toda vez que el espacio urbano se situará dentro del territorio monástico ${ }^{15}$. El cenobio recibiría en compensación un tercio del nuevo burgo y tres casas próximas al monasterio.

El documento fundacional nos dibuja novedades básicas en tres categorías sobre el territorio: morfología, economía y sociedad.

\section{Morfología}

El nuevo espacio urbano venía, pues, a dialogar con el escenario anterior, del cual necesitaba, forzosamente, los caminos, las vías de comunicación. La obra de E. Ferreira Priegue acerca de este sujeto nos aporta poca luz en cuanto a datos concretos de esta época, pues la mayoría de referencias de las que se hace eco son posteriores a la fundación o están basadas en un documento falso del 791 . Su interés no es discutible, pues aún siendo falso para tal año, no deja de reflejar una realidad vigente en algún momento de la Edad Media. La razón por la que lo descartamos es que no aborda el espacio concreto de Monforte ${ }^{16}$.

Con todo, su obra nos induce a pensar en un Monforte nudo de caminos entre los provenientes de Sarria, Quiroga, Castro Caldelas y Belesar, discurriendo en este último, parcialmente, por una anciana vía romana. Y, aún sin poder afirmar si estas vías son una causa para la fundación en este lugar o su consecuencia,

\footnotetext{
11 Luis García de Valdeavellano, Sobre los burgos y los burgueses de la España Medieval, Madrid, Real Academia de la Historia, 1960, pág. 131.

12 Manuel Risco, España Sagrada: Theatro geographico-historico de la Iglesia de España, origen, diuisiones y limites ... antiguedad, traslaciones y estado ... en todos los dominios de España, y Portugal, con varias disertaciones criticas..., Tomo XL, Madrid, 1796, págs. 226-227.

13 Se trata de un legajo suelto, mecanografiado y de autor desconocido, procedente de un archivo familiar monfortino, inédito, en el que se hace una traducción al castellano del documento fundacional, el cual, muy probablemente, tuviera ante sí el traductor, toda vez que coincide plenamente con la transcripción latina publicada en La España Sagrada, con la excepción del escatocolo, que esta última no recogía, y las variaciones lógicas de la traducción.

${ }^{14}$ Optamos por la fórmula conde en Lemos para diferenciar a don Froila Díaz y sus inmediatos sucesores, comites, tenentes regios en la tierra de Lemos, de los condes de Lemos bajomedievales.

15 G. VÁzquez Sueiro, Historia de Monforte..., pág. 140.

${ }^{16}$ Elisa Ferreira Priegue, Los caminos medievales de Galicia, Ourense, Museo Arqueolóxico Provincial de Ourense, 1988 (Boletín auriense, Anexos: 9), págs. 225-226.
} 
sí que nos permite vislumbrar la preexistencia al burgo de algunos caminos en diferentes puntos de Lemos, tales como el cruce señalado con una mámoa entre Teilán y Bóveda ${ }^{17}$.

Sea como fuere, para el nuevo burgo de Pino hay tres elementos que parecen claves: la situación estratégica del monte de San Vicente sobre el llano de la comarca de Lemos, que con sus 75 metros sobre éste, es visible en algunos puntos a casi diez kilómetros, un lugar, pues, muy propicio para albergar algo que distinguir del entorno; la existencia previa de la iglesia de San Vicente sobre la cima del monte y de la de Santa María a sus pies; y finalmente, el puente salvando el Cabe, lo cual reforzaría, más que ninguna otra cosa, su papel como nudo de comunicaciones.

¿Qué sabemos del puente? Pese a que la tradición local le da origen romano, la mención más antigua que conservamos es del año 1193, décadas después de la fundación del burgo, en un documento de extraordinario interés para todo lo que estamos tratando, pues nos lo pone en relación con la red de caminos públicos y el propio burgo: in terra de Lemos, in Pino... super ripam fluuii de Caue inter viam publicam qua itur ad ipsum burgum de Pino ... im principium pontis iam dicti fluminis ${ }^{18}$.

Sin embargo, dos años antes Alfonso IX ya nos dejaba entrever la existencia del puente. Por entonces, confirmaba el coto que Alfonso VII había establecido sobre las tres casas de la populatura monasterio, así como el coto sobre todo el monte, incluyendo los molinos y la iglesia de Santa María, y las cortes al otro lado del $\mathrm{Cabe}^{19}$, un lugar que podemos localizar con meridiana claridad justamente al otro lado del puente, toda vez que cuando las madres clarisas se instalan en la villa, ya en el siglo XVII, elegirán el lugar das Cortes, justo al lado occidental del puente ${ }^{20}$.

Establecidos esos tres elementos de consideración, las hechuras urbanas del burgo nos adentran en un capítulo que podríamos calificar de urbanismo románico del que, desgraciadamente, poco podemos decir. Según la propia carta fundacional, el emplazamiento de esa nueva población sería ad radicem del monte, una fórmula muy semejante a la empleada en el 915 para referirse a la iglesia de Santa María, justo en el llano. Sin poder descartar del todo que esta pudiera ser la localización de tal burgo, la ausencia de mayores referencias, de restos $\mathrm{u}$ otros datos que señalen a este lugar, nos invitan a pensar que ese radicem no

\footnotetext{
17 E. Ferreira Priegue, Los caminos medievales..., pág. 228.

18 Documento citado por E. Ferreira Rriegue, Los caminos medievales..., pág. 227.

19 C. Rodríguez Fernández, La colección diplomática de San Vicente..., doc. núm. 4, págs. 242-243, n. 4.

${ }^{20}$ Inventario del Archivo del Monasterio de San Vicente del Pino, realizado en 1821, manuscrito, papel, 198 folios, inédito, conservado en una colección particular de Monforte de Lemos, fol. 61v-62r.
} 
se traduciría exactamente bajo el monte, sino en su falda, en el mismo espacio aproximado donde después se ubicará la villa amurallada.

Además, la preexistencia de la iglesia de San Vicente nos obliga a pensar en algún camino de acceso a la misma, a la cima del monte. El modo más natural de hacerlo, único hasta bien entrado el siglo XX, es el protagonizado por la Rúa Vella, un elocuente nombre. De existir un cierto eje de San Vicente al puente podríamos establecer uno casi lineal merced a la sucesión de la Rúa Vella y la Rúa Nova, apenas interrumpidos y desviados por el paso de los lienzos de la muralla, posteriores al menos en su factura actual. ¿Podría ser esa Rúa Vella el emplazamiento original del burgo? Nada podemos afirmar salvo las conjeturas anteriormente apuntadas.

$\mathrm{Y}$ en el mismo camino de las conjeturas, podemos plantear otra igualmente atractiva. Es evidente que la iglesia de San Vicente debió tener unos dextros circundándola. Si establecemos un espacio más o menos circular de unas tres hectáreas adaptadas a la topografía del monte, sus límites nos llevan a la calle de la Falagueira, eje fundamental de la villa bajomedieval, que actuaba como anillo, adaptado a la curva de nivel del monte, entre las puertas Nuevas y de Pescaderías.

Buscando una conclusión a esta confusa maraña de suposiciones y conjeturas, y apenas reflexionando sobre el pequeño tamaño que inicialmente tendría ese nuevo burgo y aplicando el principio de la navaja de Ockham en pos de la solución más sencilla, apostamos por situar ese inicial urbanismo como un eje, no en la raíz exacta del monte, sino en su falda, bien sea en el propio camino hacia San Vicente, bien sea en sentido horizontal en la mitad de la ascensión al mismo (ver Imagen).

\section{La actividad económica}

Hemos mencionado ya abundantemente la relevancia del factor económico en la fundación y la existencia misma del burgo, ahora apenas pretendemos profundizar en un tema ya apuntado: las ferias y mercados. Si aparecían ya en el acta fundacional, serán un elemento constante en las confirmaciones regias de Alfonso VII y Alfonso IX (el cual amplía el monto total que obtiene el cenobio desde el tercio hasta la totalidad de las ferias), testimonio último de la rentabilidad que éstas entrañaban para el monasterio. Pero, ¿qué datos concretos tenemos? Los privilegios regios apenas avanzan un poco al hablarnos de las kalendas, que seguramente debamos entender como un mercado mensual por cada primer día de es $^{21}$.

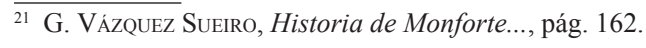


Fuera de la documentación de San Vicente, nos hacemos eco de una tesis recientemente publicada para llevar esta cuestión al extremo de la horquilla cronológica que nos hemos dado. Según dicho estudio, la villa de Monforte habría recibido un privilegio de Alfonso X para celebrar feria franca mensual en 1238, así como un mercado semanal, igualmente franco ${ }^{22}$.

Desde luego, estas concesiones no serían una novedad para la villa, pues ya hemos visto que ferias y mercados existían desde, al menos, un siglo antes. La novedad más bien estriba aquí en que sea franca, lo cual parece un cambio de equilibrio en el apoyo real en torno a este sujeto, desde un recurso a entregar a los monjes de San Vicente, hacia una apuesta por los comerciantes y mercaderes que podrían, ahora sí, colocar sus productos libres de tributos.

\section{La sociedad}

Las únicas informaciones que tenemos de los primeros habitantes del nuevo burgo son las que nos dan o inferimos del documento fundacional: que los condes llaman a cualquier persona a asentarse en la población y que, por efecto de la economía, su composición será muy diferente de la del inmenso medio rural agrario circundante. Sin embargo, el desarrollo del siglo XII tiene otros dos datos que cobran particular interés si se presentan juntos y que podrían ser los primeros testimonios de pugna entre la comunidad urbana y el cenobio.

Por un lado, nos detenemos en la mención a un documento no conservado en la actualidad según el cual, el propio Raimundo de Borgoña habría tenido que confirmar al monasterio sus posesiones ante la malignidad con que algunos quemaron o rompieron las escrituras del Archivo ${ }^{23}$. Por otro, en algún momento hacia finales del siglo XII o comienzos del XIII (aunque creemos que siempre después de 1193 por el topónimo utilizado), el rey Alfonso IX concede al cenobio el derecho a nombrar al clero secular de la villa, y añade et defendo firmiter quod nullus caballarius nec rico homo nec aliquis aliue contrariet eos super hoc nec demandet quicquam ipsis clerici ${ }^{24}$. La pregunta es evidente, ¿se refería el monarca a algún contingente social concreto del burgo/villa? ¿Había caballeros disputando el poder de San Vicente? ¿Tanto como para reaccionar violentamente contra él?

Así pues, morfología, economía y sociedad son los elementos de diferenciación del burgo con respecto a la inmensidad rural. Y ¿qué hay más distintivo

\footnotetext{
${ }_{22}$ María del Mar López Pérez, Ferias y mercados en Castilla al final del Antiguo Régimen, tesis doctoral inédita dirigida por Tomás García-Cuenca Ariati, Madrid, Universidad Complutense de Madrid, Facultad de Geografía e Historia, 2004, pág. 315.

23 M. Risco, España Sagrada..., pág. 227.

${ }^{24}$ C. Rodríguez Fernández, La colección diplomática de San Vicente..., doc. núm. 12, pág. 255.
} 
que una situación jurídica particular?, ¿un fuero?, ¿acaso un concejo? ¿Qué ente diferente conocerá esta tierra de Lemos plenomedieval en el corazón de San Vicente del Pino?

Acerca de un estatus foral particular no hemos encontrado pruebas ni indicios concretos que nos permitan afirmar nada al respecto. Un mejor panorama, por el contrario, somos capaces de dibujar en el caso de una institución concejil.

El concejo de Monforte, esa institución particular frente al contexto circundante, es una herencia netamente plenomedieval para esta ciudad. Para justificar esta afirmación nos hacemos eco del documento de 1204, por el que Alfonso IX concede a San Vicente los fumazgos de la villa y varias parroquias del entorno, especificando que lo hace con el consenso del Concilii de Monteforti ${ }^{25}$. Así pues, apenas empezado el siglo XIII ya existía un concejo, que en opinión de una voz tan autorizada como E. Pardo de Guevara, estaría ya gozando de la suficiente madurez como para desafiar el poder del monasterio, razón por la que el monarca se veía obligado a entregarle nuevas prebendas a la casa benedictina ${ }^{26}$.

No es adjetiva la expresión "nuevas prebendas". A lo largo del siglo XII los monarcas fueron favoreciendo al cenobio en repetidas ocasiones: primero Alfonso VII (un tercio de la población, un tercio de las ferias, las kalendas, el coto sobre tres casas y la facultad de nombrar al clero secular) y más tarde Alfonso IX, confirmando todo lo anterior y señalando el monte, los molinos y las cortes del otro lado del río como parte integrante del coto monástico. Será este mismo rey quién acelere el ritmo de concesiones, pues entre la confirmación de 1191 y la nueva concesión de 1204, se dirigía nuevamente al monasterio en 1199, lo hacía para confirmar nuevamente todo lo ya dado (mencionando, esta vez sí, explícitamente al puente) y añadirle el control de todas las iglesias locales hechas o por hacer y cuatrocientos sueldos en perpetuo en concepto de mitad de las ganancias del portazgo de la villa, conmutando así una tasa proporcional por una cantidad fija, todo ello para resarcir las pérdidas territoriales del colegio benedictino por la fundación ${ }^{27}$.

La cuestión es: ¿estaría en esos momentos el monarca compensando tan sólo las pérdidas lógicas de la fundación urbana en territorio monacal o también el poder creciente del concejo? Los primeros documentos inciden en la primera opción (lo cual tampoco es excluyente para con la segunda), aunque, no debemos

\footnotetext{
${ }^{25}$ C. Rodríguez Fernández, La colección diplomática de San Vicente..., doc. núm. 7, págs. 247-248.

${ }^{26}$ Eduardo Pardo de Guevara y Valdés, Los Señores de Galicia. Tenentes y Condes de Lemos en la Edad Media, vol. 1, A Coruña, Fundación Pedro Barrié de la Maza, 2000 (Galicia histórica), pág. 54.

27 C. Rodríguez Fernández, La colección diplomática de San Vicente..., doc. núm. 6, págs. 245-246.
} 
olvidarlo, en todo momento se nos dibuja un tercio de la villa bajo control del monasterio y una serie de privilegios crecientes, pero no lo que ocurre con los dos tercios restantes ni con el resto de posibles impuestos y propiedades comunales (ni su gestión hasta el momento de la entrega a San Vicente), por lo que no es descartable la posición de G. Vázquez Sueiro y Pita Andrade, que retrotrajeron la génesis del ente concejil hasta Alfonso $\mathrm{VI}^{28}$ (es decir hasta, grosso modo, los propios orígenes del burgo), hipótesis que también cuenta con la opinión favorable de E. Pardo de Guevara ${ }^{29}$.

Por nuestra parte, no vamos a aportar más a la discusión, salvo reseñar cómo el cenobio debió de ganar alguna importante batalla al concejo (o enjugar una importante derrota) en 1223, momento en que, de nuevo Alfonso IX, ordena al propio ente que ninguna voz se amortice en Monforte sin la aprobación del mayordomo de San Vicente ${ }^{30}$.

Cerraremos este capítulo con una última reflexión en torno a la figura de los alcaldes. En un inventario inédito de los fondos archivísticos de las casas consistoriales realizado en el año 1800, hoy en una colección particular, se cita una confirmación en 1314 de Alfonso XI de un privilegio dado por el rey don Fernando, para que el concejo de Monforte eligiera dos alcaldes ${ }^{31}$. Por cercanía cronológica, la primera opción es que este monarca fuera Fernando IV, fallecido apenas dos años antes, sin embargo, debemos añadir otro dato que pudiera, ora poner en tela de juicio la identidad de este don Fernando como el cuarto de su nombre, ora la novedad del privilegio: se trata de un documento de 1260 y conservado entre los fondos del monasterio de Ferreira de Pantón. En él aparece la siguiente forma entre los confirmantes: alcaldibus Montis Fortis Iohannis Petri, dicto Eamin, et Dominicus Moniz brachio de commun ${ }^{32}$. Las preguntas que nos surgen son evidentes, ¿existían ya dos alcaldes antes de dicho privilegio? ¿Sería en realidad una concesión de Fernando III? Y más aún, ¿qué quiere decir la fórmula brachio de commun?Al no encontrarle parangón, apenas podemos aventurar la hipótesis de un alcalde electo por el común frente al segundo alcalde, tal vez electo por el monasterio como proponía G. Vázquez Sueiro ${ }^{33}$.

\footnotetext{
${ }^{28}$ G. VÁzquez Sueiro, Historia de Monforte..., págs. 194-195.

29 E. Pardo de Guevara y Valdés, Los Señores de Galicia..., pág. 55.

30 C. Rodríguez Fernández, La colección diplomática de San Vicente..., doc. núm. 11, pág. 254.

31 Inventario del Archivo de las Casas Consistoriales de Monforte, realizado en el año 1800, manuscrito, papel, 23 folios, cubierta de pergamino, inédito, conservado en una colección particular de Monforte de Lemos, fol. 17r.: "1314. Privilegio del rey don Fernando, confirmado por el rey don Alonso, para que el concejo de Monforte nombre dos alcaldes".

32 José Ignacio Fernández de Viana y Vieites, Colección diplomática del Monasterio de Ferreira de Pantón, Lugo, Excma. Diputación Provincial de Lugo, 1994, doc. núm. 18, págs. 32-33.

33 G. VÁzquez sueiro, Historia de Monforte..., págs. 194-195.
} 


\section{La viLla de Monforte}

Decíamos que no aportaríamos más a la discusión sobre el arranque de la institución concejil, tal vez porque lo haga cuando lo haga, podemos señalar su génesis, como muy tardía, en los comienzos del siglo XIII -y por tanto seguir defendiendo su "novedad" en el Monforte plenomedieval-, pero, sobre todo porque preferimos centrar nuestros esfuerzos en dar un paso más y repensar algunos de esos documentos.

Hemos avanzado un cambio importante en la nomenclatura, el concejo aludido en 1204 no es ya de Pini, sino de Monteforti. La primera mención conocida al topónimo actual hay que buscarla apenas cinco años antes, en el documento dado por Alfonso IX en 1199. Así pues, si Pino es, en origen, anterior al periodo plenomedieval, Monforte es un nombre de finales del siglo XII, heredero de los cambios en él producidos. Y puede no ser baladí esta última afirmación.

Avancemos con cautela. No parece ofensivo a la prudencia cuestionarse el porqué el monarca se dirige en tres ocasiones en menos de quince años (1191, 1199 y 1204) a la villa monfortina, las tres para ampliar las concesiones dadas al monasterio. ¿Qué ocurre? ¿Qué cambia entre 1191 y 1199 para que sea precisa la intervención regia? ¿y entre 1199 y 1204? En este año ya tenemos claro un nuevo agente, y la explicación del incremento en las concesiones regias parece lógica a la luz de la teoría de E. Pardo de Guevara: el rey ayuda al monasterio para compensarlo o favorecerlo en la lucha con el concejo. Pero, ¿y en 1199? ¿ocurriría algo similar? Es probable, aunque no teorizaremos sobre ello, apenas queremos hacer notar una importante coincidencia. En 1199 se cita por primera vez el topónimo Monte Forti, el monte fuerte, algún elemento tiene que haberse desarrollado para que se derive semejante apelativo (una torre, por ejemplo, al calor de la nobleza secular heredera de Don Froila Díaz), lo cual nos plantea una inmediata pregunta iha mudado algo para que sea preciso un nuevo nombre? ¿designan estrictamente a lo mismo?

Sin poder responder a estas cuestiones, no queremos dejar pasar la oportunidad de una pertinente reflexión, ¿por qué el monasterio seguía reclamando pérdidas casi una centuria más tarde de la fundación del burgo?; ¿había sido una inversión fallida? ¿Estaba cambiando algo en esta última década del siglo XII y era sobre eso sobre lo que se compensaba ahora al cenobio? No afirmaremos tanto, pero sí plantearemos dos interesantes coincidencias en el documento del 1199: por un lado, es la única vez en que la voz Monte Forte coincide con Pino para referirse a la población (sí que lo hará en una concesión al monasterio de 1218, pero, para entonces, Pino ya refiere a San Vicente y Monforte a la localidad), bajo la fórmula Monti Forti qui olim dicitur Pinus; por otro, es la última vez que dicho enclave recibe la denominación de burgo, 
pues todos los documentos de los comienzos del siglo XIII hablarán ya de la villa de Monforte ${ }^{34}$; y, finalmente, es la primera vez que se hace referencia al portazgo de la villa ${ }^{35}$.

El interés monástico por este último impuesto, cuyo valor fue estimado en 800 sueldos por el monarca, al entregarle la mitad de esa cantidad como cuota fija, nos hacen descartar que el burgo ya casi centenario hubiera sido un fracaso en términos económicos. Ese portazgo de la villa es el testimonio último de un movimiento evidente de personas y mercancías, seguramente a vender en las ferias. Es el balance del éxito del viejo burgo comercial. ¿Se compensa, por tanto, al cenobio porque la comunidad local está ganando en autonomía -recordemos que en 1204 ya tiene un concejo sin lugar a dudas- y se está transformando en una villa?

¿Nuestra vieja entidad singular de población en la inmensidad rural, el burgo de Pino, habrá dado en este momento un paso hacia una mayor autonomía local, deviniendo en algo más desarrollado y más independiente como villa de Monforte? ¿Es, directamente, este cambio de siglo el momento en que nace el concejo monfortino? Es nuestra posibilidad preferida, toda vez que no existen menciones previas al ente concejil ni a ninguno de sus cargos, si bien no podemos asegurar nada. También, cabría la posibilidad alternativa de que, aspectos como la elección de alcaldes, antes tratada, constituyeran esos pisos de autonomía frente a una institución preexistente y menos desarrollada.

En todo caso, ¿ha pasado el monasterio de permitir una realidad diferente bajo sus pies a tener que otear el mundo rural, en el que los benedictinos se sentían más cómodos, desde una atalaya urbana? Desde luego, eso justificaría suficientemente su exigencia de nuevas compensaciones y prebendas.

Recuperaremos aquí nuestra reflexión de un monte fortalecido. ¿La villa necesitaría un mayor espacio que el burgo? ¿ese espacio estaría amurallado? ¿se amurallaría en este momento?

Los abundantes restos que siguen en pie, tanto de las murallas como del castillo condal son abiertamente bajomedievales, además de muy remozados tras las consecuentes destrucciones de la revuelta Irmandiña ${ }^{36}$. Sin embargo, el horizonte de siglos anteriores porfía, afortunadamente, en reaparecer ante nues-

\footnotetext{
34 Sirvan como ejemplo la donación otorgada por Alfonso IX al Monasterio de San Vicente en 1208 (Monte de Vilar de Mouros) y la confirmación papal de todas las franquicias en 1213, en ambos casos las fórmulas utilizadas son populatione o populatione villae de Monti Forti: C. Rodríguez Fernández, La colección diplomática de San Vicente..., docs. núm. 8-9, págs. 249-251.

${ }^{35}$ C. Rodríguez Fernández, La colección diplomática de San Vicente..., doc. núm. 6, págs. 245-246.

${ }^{36}$ Ernesto Iglesias Almeida, "Las fortificaciones monfortinas", Cuadernos de Estudios Gallegos, XLVIII, fasc. 114 (2001), pág. 251.
} 
tros ojos, en primer lugar a través de la documentación del monasterio de San Vicente, y más concretamente de un aforamiento realizado a fines del siglo XIII, en 1295, a un alfayate morador as Portas Novas (elemento de la muralla que ha llegado, con ese mismo nombre, hasta la actualidad) ${ }^{37}$; a lo que se añade, para la misma centuria, el testimonio de la crónica de Fernando IV, según la cual Fernando Rodríguez, primogénito de Esteban Fernández, señor de Lemos y Sarria, habría acudido ante la reina María de Molina para implorar la devolución del castillo de Monte Forte, en Galicia ${ }^{38}$.

Sin embargo la cuestión principal sigue siendo, ¿podría haber alguna construcción del siglo XII? Dos testimonios de diferente naturaleza hablan en favor de esa posibilidad. Por un lado, la aparición del tenente de Lemos Álvaro Rodríguez de Sarria en el poema de Almería, donde queda inmortalizada su importancia por asegurar las fortalezas de la guerra en tierra lucense ${ }^{39}$. Por otro, más relevante, la presencia de signos lapidarios en una puerta cegada de las murallas monfortinas, en concreto junto a la puerta de la Cárcel Vieja (la más meridional del conjunto amurallado monfortino), que, en opinión de E. Iglesias Almeida, situaría esos sillares en los finales del siglo XII, justamente la fecha en que aparece nuestro topónimo de Monforte ${ }^{40}$.

Este dato tiene una segunda lectura de interés, pues hablamos de la puerta más meridional del conjunto, fuera cual fuera la traza del burgo, el espacio que encerrarían estos sillares sería necesariamente mucho más amplio. ¿Alcanza la nueva villa un primer perímetro amurallado de iguales o semejantes dimensiones al bajomedieval que conocemos hoy en día? Indudablemente, esto respondería a dos cuestiones fundamentales, por un lado nos aseguraría que la conversión del burgo en villa no sólo se manifiesta en una mayor autonomía local, sino que se acompaña de un crecimiento espacial, de una nueva configuración urbana, más rica y más desarrollada; por otro, justificaría bastante bien las constantes concesiones regias aludiendo a las pérdidas de San Vicente un siglo más tarde de la fundación del burgo, no estaría ya compensando los viejos perjuicios de 1104, sino los nuevos de finales del siglo XII.

En el supuesto de que la nueva villa estuviera ya alcanzando las dimensiones aproximadas del recinto amurallado que hoy conocemos, ¿qué pasaría con la morfología urbana? Nos volvemos a plantear en este punto la misma cuestión

\footnotetext{
37 C. Rodríguez Fernández, La colección diplomática de San Vicente..., doc. núm. 22, págs. 275-276.

38 E. Pardo de Guevara y Valdés, Los Señores de Galicia..., págs. 122-124.

39 E. PARdo de guevara y valdés, Los Señores de Galicia..., págs. 65-67. El texto exacto al que nos referimos del poema de Almería reza de la siguiente manera: Fovisti parvos, firmans certamine magnos / talibus ac tantis tractus patribus generosis / Alvarus ecce furit Mauros quoniam probus odit / Navia dat vires, Monsniger dat quoquer plures / terraque Lucensis munimina praestit ensis. (Salvador MARTíNEZ Santamarta, El "poema de Almería” y la épica romántica, Madrid, Ed. Gredos, 1975, págs. 40-41.

${ }^{40}$ E. Iglesias almeida, “Las Fortificaciones...”, pág. 258.
} 
que en el caso del burgo. En este caso el emplazamiento concreto no está en duda, pero ¿qué calles estarían habitadas? La lógica nos dice que, de estar construída ya la cerca, los dos grandes ejes que comunicaban sus tres puertas serían las vías privilegiadas por la población: la calle Falagueira y la calle Zapatería.

Desafortunadamente, de ninguna de ellas tenemos información para el siglo XIII, la más pretérita mención que conservamos para ambas data ya de las centurias siguientes. En el caso de la Falagueira debemos avanzar hasta el año 1368, cuando Afonso Eanes afore una casa, limítrofe con otra, en esta vía monfortina ${ }^{41}$; aún más debemos aguardar para encontrar referencias a la Zapatería, en concreto hasta 1438 , con motivo de un aforamiento por parte del monasterio ${ }^{42}$, si bien ya en 1401 se nos dejaba entrever su existencia a través de la donación del capellán de Ferreira de Pantón al mismo monasterio de una casa en Monforte, llevada por un zapatero y a cambio de unas misas por el alma de Francisca da Çapateria ${ }^{43}$.

Curiosamente, la vía de la que conservamos testimonio más antiguo no se trata de ninguna de estas dos, ni de otras secundarias que hallamos bien atestiguadas para el siglo XV, sino de una calle extramuros, la Rúa dos Ferreiros. De ella tenemos ya noticia en 1316 cuando el abad Diego Garçía afora en este lugar una casa, que había sido, precisamente, de un ferreiro ${ }^{44}$.

\section{UNA VILLA, TRES PODERES}

La conversión del viejo burgo de Pino en la villa de Monforte no requiere del amurallamiento de ésta, si bien, dado el cambio de topónimo, sería una opción verosímil. Sin embargo, no podemos descartar que tal nombre se le diera simplemente por la existencia de alguna fortificación en su cúspide. En este sentido, R. Balsa de la Vega, iba mucho más allá a comienzos del siglo XX y afirmaba la existencia de una torre a modo de donjon dominando el monte de San Vicente desde la propia fundación del burgo y la tenencia de don Froila Díaz ${ }^{45}$. No obstante, no hay mayor testimonio para afirmar tal cosa.

La propuesta de Balsa de la Vega llama nuestra atención sobre un lugar privilegiado de la villa de Monforte, la cima del monte de San Vicente. De ella sabemos que estaba ocupada, mucho antes de la fundación del burgo, por la iglesia de San Vicente del Pino, y que, con el trascurrir de los siglos, fue convirtiéndose

\footnotetext{
${ }^{41}$ C. Rodríguez Fernández, La colección diplomática de San Vicente..., doc. núm. 27, págs. 285-286.

42 C. Rodríguez Fernández, La colección diplomática de San Vicente..., doc. núm. 179, págs. 611-612.

43 J.I. Fernández de Viana y Vieites, Colección diplomática del Monasterio de Ferreira..., doc. núm. 87, págs. 108-109.

44 C. Rodríguez Fernández, La colección diplomática de San Vicente..., doc. núm. 19, págs. 269-270.

${ }^{45}$ Rafael BAlsa DE LA VEGA, Catálogo-inventario monumental y artístico de la provincia de Lugo: lo llevó a término por Real Orden de 21 de junio de 1911, papel, manuscrito, 208 folios, 1912, págs. 163-164.
} 

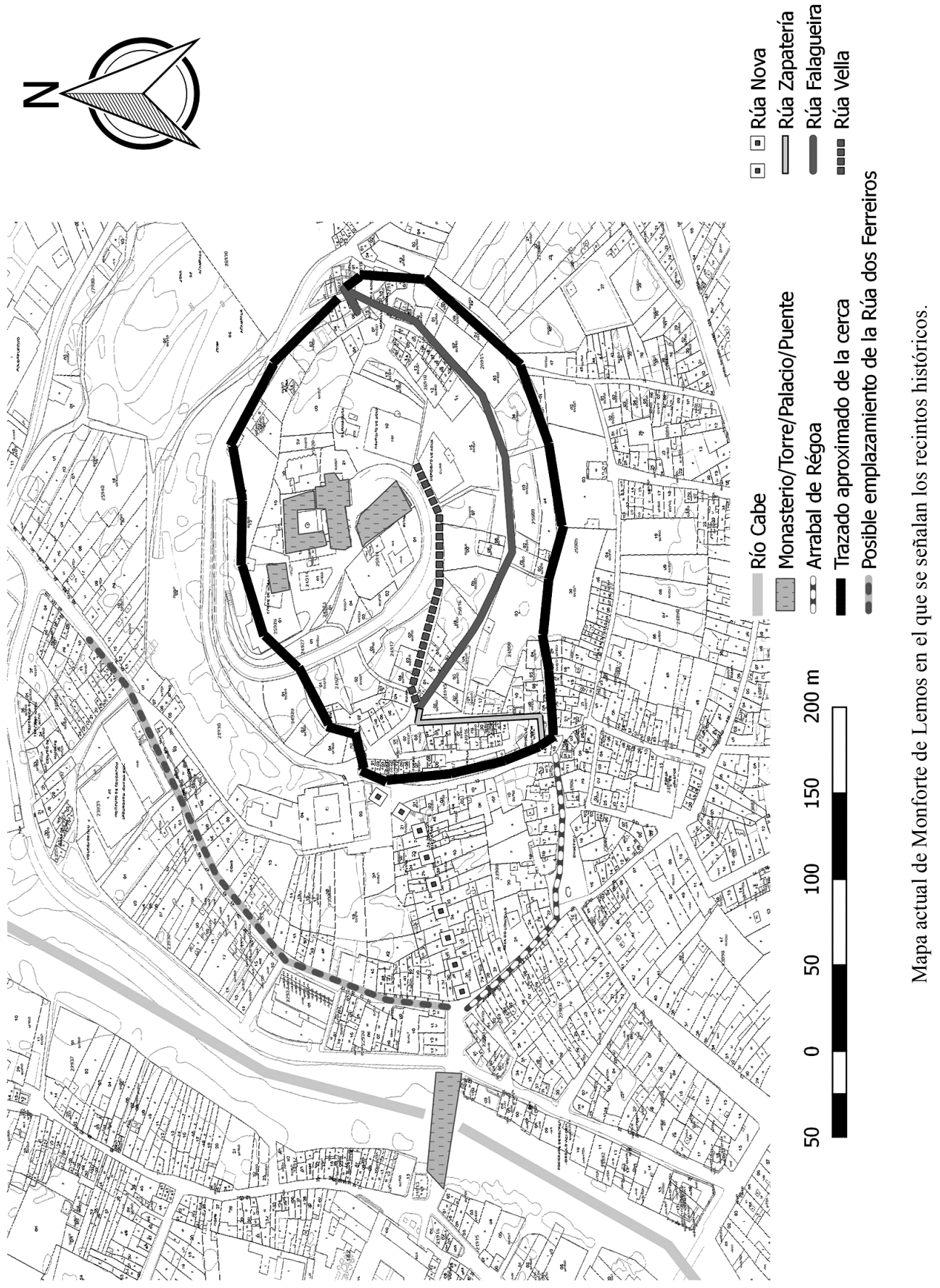
en el mejor exponente del tablero de ajedrez de los poderes locales que era la villa: torre de homenaje, monasterio, palacio condal, y todo ello intramuros de una villa con concejo propio. Aunque todas las construcciones que hoy conservamos en ese espacio son claramente posteriores al periodo que nos ocupa, pues todas proceden de la Edad Moderna, una lectura atenta a lo que tenemos puede resultar de gran interés.

El monte de San Vicente es una elevación de unos 75 metros sobre la llanura del valle de Lemos. En su última curva de nivel se hallan los tres edificios de nuestro interés: la torre, el monasterio y el palacio condal, estos dos últimos prácticamente en línea recta (de unos 120 metros en su totalidad) y tal vez arrancando desde una cota muy ligeramente inferior a la del cenobio que, ocupando el punto más alto de la colina llega a superar en su campanario la propia atalaya de la torre. Ésta última, es una construcción muy remozada tras la revuelta irmandi$\tilde{\text { na }}{ }^{46}$, de 30 metros de altura y unos $175 \mathrm{~m}^{2}$ de superficie, dibujo cuadrangular de muros de algo más de 13 metros de largo y unos 3 de grosor ${ }^{47}$. A su alrededor, se abre un espacio fortificado de unos $1493 \mathrm{~m}^{2} \mathrm{y}$ forma casi circular.

Desde la torre median apenas 12 metros hasta la esquina norte del edificio monacal. Éste, compuesto por cenobio y su inmediata iglesia, constituye un frente de unos 55 metros de largo. El templo, por su parte, presenta planta de cruz latina, con una sola nave de unos 14 metros de ancho. Desde los pies y hasta el altar mayor se cuentan unos 46 metros, por 25 de ancho a la altura del crucero, que acoge, en el lado del evangelio, la capilla-camarín de Nuestra Señora de Montserrat. A su lado sur se abre en la actualidad una plaza, a la cual salen las dos puertas laterales del templo, y a la que también se asoma el palacio condal, de los siglos XVI-XVII, convertido -junto al propio Monasterio- en Parador Nacional en el año 1997. La distancia entre la esquina del palacio y la de la iglesia de San Vicente es de apenas 8 metros. Por su lado opuesto, como aún puede observarse en algunas fotografías antiguas, se accedía desde la villa siguiendo la Rúa Vieja ${ }^{48}$.

En el flanco norte de la iglesia se localiza el edificio cenobítico, construido en torno a un claustro cuyo patio alcanza una superficie de $188 \mathrm{~m}^{2}$.

Todo ello nos dibuja una ensalada de cifras, medidas y datos de los que queremos rescatar dos a nuestro juicio muy importantes. El primero, las dimensiones del templo: dificilmente el existente en época plenomedieval pudo ser más grande, toda vez que cubre la práctica totalidad del espacio llano de la cima,

\footnotetext{
${ }^{46}$ E. Iglesias Almeida, "Las Fortificaciones...”, pág. 254.

47 E. Iglesias Almeida, "Las Fortificaciones...”, pág. 272.

${ }^{48}$ Monforte en imaxes. Un século de historia (1863-1963), León, Excmo. Concello de Monforte de Lemos; Evergráficas, 1991, pág. 43.
} 
iniciándose la pendiente de modo casi inmediato en la cabecera y apenas dejando unos metros a sus pies. El segundo, aunque más relevante, es la posición del claustro al norte. Nada sabemos del edificio cenobítico anterior, aunque parece lógico que debió existir un claustro. ¿Estaría construído también al norte? ¿Por qué esta anomalía? ¿Por qué un cambio en el siglo XVI en el supuesto de estarlo hasta entonces al sur? Traeremos en este punto apenas un dato más para este debate. A finales del siglo XIV, don Fadrique, duque de Arjona y conde de Lemos, solicitó permiso al Papa para trasladar el cenobio benedictino bajo la cresta del monte, toda vez que en su cima le estorbaba en sus propósitos de ampliar sus aposentos ${ }^{49}$. Se nos ocurren muchas posibilidades al respecto mas, si esos aposentos estuvieran adosados a la torre, el edificio cenobítico tan sólo sería un problema de encontrarse justamente en el lugar en que lo hace hoy día, y tal vez por ello, ya en la Edad Moderna, los descendientes en el linaje de Don Fadrique prefirieran no reeditar el viejo conflicto y trasladar su nueva residencia al flanco contrario.

Sin embargo, también podría darse el caso justamente contrario, que una eventual edificación estuviese adosada a la torre, ocupando parte del espacio del actual claustro, de modo y manera que el existente a la sazón estuviera en el preceptivo lado sur. Serían entonces las ambiciones de un majestuoso palacio del duque las que chocarían con la localización de la iglesia, ambiciones moderadas por parte de sus sucesores en la Edad Moderna, hasta el punto de contentarse con un intercambio de lugares con la comunidad benita.

Fuera cual fuera la realidad, no podemos renunciar a ver en la petición del duque de Arjona una evidente pugna por el espacio del poder. A fin de cuentas, para ese momento la nobleza laica comenzaba a asentarse con fuerza en Monforte $^{50}$, y el hecho de compartir el protagonismo visual de la cima del monte de San Vicente con el cenobio minusvaloraba ese avance. Pero, el duque pudo percibir algo más cuando quiso sacar del espacio amurallado a la comunidad benedictina, tal vez para entonces la comunidad local y la religiosa tenían importantes problemas de incomprensión mutua, tal vez al propio duque le resultaba extraña la presencia de una comunidad de raigambre rural en pleno corazón de una realidad urbana.

Mucho más elocuentes podríamos ser acerca de los espacios del poder laico en la villa monfortina si tuviéramos mayor información sobre los del monasterio y su iglesia. De estos, más allá de su atestiguada presencia, apenas tenemos datos anteriores y posteriores, pero ninguno coetáneo a los procesos de nuestro interés.

\footnotetext{
${ }_{49}$ L. Moure-Mariño, Apuntes para la historia..., pág. 57.

${ }^{50}$ E. Pardo de Guevara y Valdés, Los señores de Galicia..., págs. 251-292.
} 
El monasterio del Pino es, pues, la siguiente parada ineludible, sede de poder territorial, jurisdiccional y espiritual. La iglesia abacial de San Vicente mártir era, también, la sede parroquial de la villa, toda vez que el cenobio benedictino tenía conferida la cura animarum parroquial ${ }^{51}$, junto a la posesión de todas las iglesias que se construyeran en sus términos y el derecho de presentación de los sacerdotes de otras cuantas parroquias de su entorno ${ }^{52}$, además de ser titular el abad del arcedianato de $\operatorname{Lemos}^{53}$.

Así, pues, la parroquia de San Vicente tenía en la monacal su templo principal. Desafortunadamente, la fábrica que debió ejercer este rol durante la Edad Media no parece haberse conservado, toda vez que la actual construcción data del siglo XVI. Según consta en el contrafuerte exterior del crucero, en el lado de la epístola, el comienzo de su construcción dataría del $1539^{54}$.

Como ya habíamos afirmado, conservamos, sin embargo, datos muy anteriores, los del año 915, de la célebre prueba caldaria. En ella, mucho antes de la fundación del burgo, se nos mencionan las iglesias de San Vicente, en la cima del monte, y Santa María a sus pies $^{55}$. Así pues, el origen de la iglesia sería claramente anterior a la época que nos ocupa. ¿Hubo una iglesia posterior? Nada podemos decir al respecto, si bien parece una opción más probable que la supervivencia de una fábrica prerrománica.

En todo caso, las únicas referencias documentales al templo son ya del siglo $\mathrm{XIV}$, es decir, al otro extremo de nuestra horquilla. Normalmente procedente de testamentos en los que son frecuentes las mandas a beneficio de las lámparas del templo ${ }^{56}$. Se nos menciona una capilla funeraria en su interior, dedicada al arcángel San Miguel $^{57}$; así como un altar dedicado a Santa Catalina, seguramente localizado a los pies del templo, toda vez que el testador pedía ser inhumado entre este altar y la pila del agua bendita ${ }^{58}$. En una donación del 1454, el oferente pedía ser sepultado entre el primer y segundo pilar de piedra, a mano derecha, empezando desde la puerta ${ }^{59}$.

\footnotetext{
${ }^{51}$ C. Rodríguez Fernández, La colección diplomática de San Vicente..., doc. núm. 85, págs. 403-419.

${ }_{52}$ El privilegio de posesión de todas las iglesias de la villa le había sido concedido a San Vicente por Alfonso IX, ed. C. Rodríguez Fernández, La colección diplomática de San Vicente..., pág. 255, n. 12. Según Antolín López Peláez, Los Benedictinos de Monforte, La Coruña, Ed. Carré, 1895, pág. 66, el derecho de presentación ascendería a un total de 10 curatos (Monte, Penela, Gándara, Seteventos, A Vide, Ribas Pequenas, Marcelle, Gullade, Vilamarín y Linares).

53 A. López Peláez, Los Benedictinos..., págs. 59-61.

54 G. VÁzquez Sueiro, Historia de Monforte..., pág. 525.

55 C. Rodríguez Fernández, La colección diplomática de San Vicente..., doc. núm. 2, págs. 237-240.

${ }^{56}$ Sirva como ejemplo el otorgado por Vicente Pérez en el año 1300, ed. C. Rodríguez Fernández, La colección diplomática de San Vicente..., doc. núm. 18, págs. 265-268.

57 C. Rodríguez Fernández, La colección diplomática de San Vicente..., doc. núm. 377, págs. 1051-1052.

58 C. Rodríguez Fernández, La colección diplomática de San Vicente..., doc. núm. 298, págs. 865-867.

59 C. Roríguez Fernández, La colección diplomática de San Vicente..., doc. núm. 279, págs. 822-823.
} 
Así las cosas, poco afortunados en la información documental, volvemos nuestra mirada hacia el ámbito material y arqueológico. En este caso, las -de nuevo- escasas fuentes nos permiten afirmar que, si no hubo una iglesia construída durante este período, románica por tanto, al menos debió haber importantes reformas en la a la sazón existente. Así lo atestiguarían el frontal de altar aparecido en el año $1940^{60}$, una pila bautismal y varios restos encontrados, ora embutidos en las paredes del templo actual, ora actuando como linde de la huerta monástica junto a la torre norte del conjunto fortificado o como material de apeo, y que E. Iglesias Almeida identificó como trozos de dovelas con el clásico ajedrezado ${ }^{61}$.

Fuera como fuere, la villa monfortina siempre tendrá como elemento original el haber tenido entre sus muros, además como sede parroquial de la comunidad local, a una comunidad benedictina, de natural raigambre rural.

Analizados ya los poderes laico y espiritual, nos resta tan sólo uno: el concejil. Fácil es de suponer que no hemos encontrado ninguna casa de concejo para acoger a éste toda vez que se trata de un fenómeno absolutamente infrecuente en la Edad Media hispana, pero, en este caso, tampoco conocemos ningún espacio predilecto para su reunión. Apenas podremos esgrimir un documento del siglo XIV en el que el alcalde mayor de la villa ejerce funciones judiciales a las puertas de las casas de morada ${ }^{62}$.

\section{HOSPITALES Y PUENTES}

Recorridos ya los tres poderes asentados en nuestra villa monfortina, sólo cabe preguntarnos por otras instituciones y construcciones que hayan condicionado la morfología y el devenir del tránsito del burgo a la villa y a ésta misma. Es así que inauguramos un último capítulo en el que recogemos dos realidades bien distintas: los hospitales y los puentes, si bien ambos con un aspecto común: su vinculación a los caminos y el movimiento de personas, algo clave en el éxito de Pino/Monforte.

El apartado de hospitales puede considerarse tan sugerente como etéreo. En general, los únicos puntos seguros que podemos fijar al respecto serían los hospitales de Sancti Spiritus y San Lázaro, el primero localizado en el arrabal de Santa María y el segundo en el de Carude de San Lázaro, ambos con sus

\footnotetext{
${ }^{60}$ Manuel Hermida Balado, Monforte de Lemos, León, Ed. Everest S.A., 1987, págs. 42-47.

${ }^{61}$ E. Iglesias Almeida, "Las Fortificaciones...", pág. 251.

${ }^{62}$ M. Lucas Álvarez y P. Lucas Domínguez, El priorato benedictino de San Vicenzo de Pombeiro..., doc. núm. 49, págs. 101-103.
} 
testimonios más antiguos en la muy Baja Edad Media ${ }^{63}$. Sin embargo, la posible existencia de un establecimiento anterior no es una idea nueva. Ya G. Vázquez planteó una posible existencia en el siglo XIII en base a un testamento en el que se cita in Lemabus et in Queiroga hospitali, noticia ésta que se suma a la teoría de López Ferreiro, quien situaba un establecimiento hospitalario en el lugar de Alberguería, en la parroquia de Ribas Altas ${ }^{64}$.

Por nuestra parte, apenas defenderemos la verosimilitud de la existencia de algún hospital en torno a los siglos XII-XIII, tanto por los datos anteriormente ofrecidos como por otros dos que añadimos: la explicación que otorga el diccionario de F. J. Rodriguez (1863) a la voz Regoa, que vincula la iglesia monfortina de Santa María (extramuros de la villa) a la regla de la Orden de San Juan ${ }^{65}$, y que, de ser cierta, nos llevaría forzosamente a ese horizonte plenomedieval, momento previo a la aparición de los primeros documentos que dan ese apellido a la iglesia; y la aparición en un documento, en tan sólo uno, fechado en 1232, de un "Comendador de Lemos" como testigo en un pleito sostenido por la Orden de San Juan (por lo demás, asentada en los vecinos Quiroga y Portomarín) ${ }^{66}$.

La existencia de una encomienda de los frailes sanjuanistas en tierras de Lemos sería una absoluta novedad, aunque no exactamente su presencia en estos momentos. No en vano, en un documento fechable entre 1188 y 1218 Gutierre Rodríguez y su mujer la condesa Elvira Osorio donan a la orden su monasterio de San Félix de Incio, bajo la condición de que éste forme una sóla bailía con quantum habent et habituri sunt fratres in $\operatorname{Lemos}^{67}$. De haberse generado así una circunscripción sanjuanista propia, lo más probable es que ésta fuera posterior al año 1214, cuando el propio rey Alfonso IX confirmaba en Lemos todas sus propiedades a la orden en todos sus reinos, y sin que entre sus testigos figurara ningún comendero local de San Juan ${ }^{68}$.

\footnotetext{
${ }^{63}$ La primera referencia explícita a un hospital en San Lázaro data del siglo XVI. Sin embargo, la aparición de la advocación nos permite retraer su posible presencia en una centuria, hasta 1431. C. RodRíguEZ FERNÁNDEZ, La colección diplomática de San Vicente..., págs. 501-502, núm. 126.

${ }^{64}$ G. VÁzquez Sueiro, Historia de Monforte..., pág. 755.

${ }^{65}$ La definición de la voz "Regoa" reza de la siguiente manera: "Encomiendas del Orden de San Juan en Monforte, León y en el obispado de Mondoñedo, en la costa del mar cantábrico, á donde pertenece la ermita de S. Andrés de Teijido. En otro tiempo vivian algunos sugetos en esas casas, segun ó conforme á una regla, régula, régola ó regoa, de donde trae el nombre". Véase en Francisco Javier RodríguEz, Diccionario gallego-castellano, La Coruña, Ed. de Antonio de la Iglesia González, 1863 [en línea], disponible en $<$ http://sli.uvigo.es/DdD/ddd_pescuda.phppescuda=regoa\&tipo_busca=lema $>$ [Consulta: 21/06/2016]. ${ }^{66}$ Isidro García TATO, Las encomiendas gallegas de la Orden Militar de San Juan de Jerusalén. Estudio y Edición documental, Vol. 1: Época Medieval, Santiago de Compostela, CSIC; Xunta de Galicia, Instituto de Estudios Gallegos "Padre Sarmiento", 2004, págs. 35-36.

${ }^{67}$ I. García Tato, Las encomiendas gallegas de la Orden Militar de San Juan de Jerusalén... Vol. 1, págs. 148-149.

${ }^{68}$ Carlos de Ayala Martínez, Libro de privilegios de la Orden de San Juan de Jerusalén en Castilla y León (siglos XII-XV), Madrid, Instituto Complutense de Estudios de la Orden de Malta (ICOMAL), 1995, págs. 396-397.
} 
El que esta posible encomienda hubiera aparecido y desaparecido sin dejar casi rastro tampoco resultaría del todo sorprendente, a fin de cuentas los siglos XII y XIII son centurias de construcción de los señoríos sanjuanistas peninsulares, con dominios en constante movimiento a través de donaciones y compraventas $^{69}$. Así, la arquitectura territorial de la orden aún no estaba fija, se seguirá moviendo, hasta el punto de que muchas de sus encomiendas desaparecerán a lo largo de los siglos XIV y XV. En nuestro caso sabemos que, al menos para comienzos del siglo XVI, la encomienda de Incio es ya una realidad, con lo que podría haber asumido para entonces el espacio de una vieja circunscripción de Lemos $^{70}$.

La cuestión que nos resta de todo ello es más que evidente, ¿se contaría entre esas posesiones en Lemos alguna en la villa de Monforte? La posibilidad de que un eventual hospital de la Orden de San Juan pudiera ser el precedente del Hospital del Sancti-Spiritus no sería, espacialmente hablando, algo inverosímil, dada la cercanía de este último a la iglesia de Santa María (a medio camino entre ella y el puente que salva el río Cabe) y la mención en el siglo XV a una casa colindante con otra perteneciente a la orden de San Juan, precisamente en este espacio junto al puente ${ }^{71}$.

Con todo, creemos pertinente sumar una reflexión: más allá de los restos materiales o documentales, lo cierto es que la existencia de algún establecimiento hospitalario en la villa monfortina o sus cercanías parece algo bastante plausible en base a su situación como nudo de comunicaciones en el contexto de la tierra de Lemos, tal y como ya hemos tratado con anterioridad, y que se refuerza por la existencia de otros establecimientos más o menos conocidos en esas mismas vías (tales como el hospital de Moreda o el que plantea Ferreira Priegue en el camino de A Parte hacia Pobra do Brollón ${ }^{72}$ ).

Nos tomaremos, finalmente, la licencia de transgredir nuestra propia horquilla cronológica en este punto antes de abandonar definitivamente la cuestión hospitalaria. Lo haremos para advertir sobre dos instituciones concretas. La primera nos lleva al año 1300, para entonces un testamento suscrito en la villa por un clérigo de San Vicente otorga una de sus mandas hospital dos Çapatei$\operatorname{ros}^{73}$. Aunque no señala el emplazamiento de este establecimiento, la pregunta es evidente ¿existiría un hospital vinculado al gremio zapatero? ¿Qué antigüedad tendría para $1300 ?$

\footnotetext{
${ }^{69}$ Carlos Barquero Goñi, Los caballeros hospitalarios durante la Edad Media en España, Burgos, Colección Piedras Angulares, 13, Ed. La Olmeda S.L., 2003, págs. 22-23.

70 Carlos Barquero Goñi, Los caballeros hospitalarios durante la Edad Media..., págs. 142-143.

71 C. Rodríguez Fernández, La colección diplomática de San Vicente..., doc. núm. 213, págs. 684-685.

72 E. Ferreira Priegue, Los Caminos medievales..., págs. 228-229.

73 C. Rodríguez Fernández, La colección diplomática de San Vicente..., págs. 265-268, núm. 18.
} 
La segunda, y más importante, es un nuevo elemento en la relación de hospitales locales, una primicia que ofrecemos en este artículo, el de un establecimiento llamado de Santa María la Madre, que nos aparece para la segunda mitad del siglo XV en un documento inédito ${ }^{74}$. Su localización precisa resulta difícil, aunque podría hallarse en el entorno del arrabal de Os Chaos, donde hasta el siglo XVII conocemos una ermita bajo la advocación de Santa María del Camino ${ }^{75}$.

Cerrando ya este último capítulo, atamos el último punto en torno al puente que salva el paso del río Cabe a la altura del propio monte de San Vicente, en la cercanías de la iglesia de Santa María. Las primeras referencias a él han sido ya ampliamente comentadas, tanto en las menciones indirecta y directa de Alfonso IX en sus documentos de 1191 y 1199, como en el documento de 1193, una venta de una casa al principio del puente que salva el Cabe en el burgo de Pino $^{76}$. La siguiente referencia conocida será ya de 1333, cuando dicha construcción se beneficia del testamento de Juan Sobrote ${ }^{77}$.

A modo de conclusión, queremos detenernos, en primer lugar, en los objetivos con los que partiamos en el presente artículo. Si la historia de Lemos es un largo ovillo que a través de la inmutabilidad del término ha ido recorriendo las diferentes etapas históricas, el trecho de ese hilo que corresponde al periodo plenomedieval ha sido el encargado de atar un nudo trascendental hasta nuestros días: el nacimiento de una realidad urbana distinta en lo morfológico, económico y social de su entorno rural, una realidad a la que llamar burgo y posteriormente villa, y cuyo nombre, Monforte, es la primera de las reliquias de este periodo que hemos conservado hasta la actualidad.

Por las mismas, podemos también concluir que, sin embargo, el paisaje rural de Lemos, y los términos y nombres de, al menos, algunas de sus parroquias, son, sin embargo, una realidad anterior, lo cual acentúa el punto y seguido de la contribuación urbana románica.

Por otro lado, constituida la institución municipal, no podemos dejar de hacer un balance de los tiempos plenomedievales como los de la conformación del segundo gran agente de poder dispuesto a pugnar por el territorio junto al ya preexistente monasterio, y el incipiente poder laico, que pese a ser anterior, no acabará de eclosionar hasta la Baja Edad Media, cuando los señores de Lemos devengan la familia nobiliar más importante de Galicia. Los tres otearán entonces

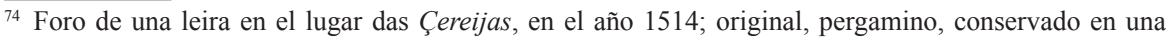
colección particular monfortina.

75 Inventario del monasterio de San Vicente, fol. $85 \mathrm{v}$.

76 E. Ferreira Priegue, Los Caminos medievales..., pág. 227.

77 C. Rodríguez Fernández, La colección diplomática de San Vicente..., págs. 277-279, núm. 23.
} 
Lemos desde lel exiguo marco físico que constituye la plataforma natural de la acrópolis del monte de San Vicente, acrópolis que, según parece, había ya acogido durante la Antigüedad el Castro Dactonium. Monasterio, villa, nobleza: tres poderes, y una sola pugna.

Y un cuarto agente de suma importancia: la Corona. Si su papel fundacional lo vislumbramos a través del tenente en Lemos, representante último del Rey, su presencia en el resto de las centurias decimosegunda y decimotercera se materializa apoyando al cenobio benedictino y al concejo local, en un difícil equilibrio en el que, probablemente, las fuentes conservadas nos trasmitan una visión trastocada del partido tomado por el monarca. El privilegio de elección de dos alcaldes, la aparición del propio concejo, las concesiones de ferias francas contradiciendo los primeros derechos otorgados a San Vicente ... todo ello nos hace preguntarnos si la corona se estaba poniendo del lado del concejo frente al monasterio, al cual, sin embargo, intentaba constantemente contentar con nuevas concesiones y prebendas. El cenobio benedictino, de profundas raíces rurales, no conecta con los problemas de la población urbana tan bien como lo harán las órdenes mendicantes.

Todas las conclusiones juntas nos llevan a una misma: el Lemos plenomedieval construía un edificio señero, un nudo particular y trascendental en su historia, un burgo, una villa, un concejo, un agente de poder.

\section{BIBLIOGRAFÍA}

Ayala Martínez, Carlos de, Libro de privilegios de la Orden de San Juan de Jerusalén en Castilla y León (siglos XII-XV), Madrid, Instituto Complutense de Estudios de la Orden de Malta, (ICOMAL), 1995.

Barquero Goñi, Carlos, Los caballeros hospitalarios durante la Edad Media en España, Burgos, Colección Piedras Angulares, 13, Ed. La Olmeda S.L., 2003.

Fernández de Viana y Vieites, José Ignacio, Colección diplomática del Monasterio de Ferreira de Pantón, Lugo, Excma. Diputación Provincial de Lugo, 1994.

Ferreira Priegue, Elisa, Los caminos medievales de Galicia, Ourense, Museo Arqueolóxico Provincial de Ourense, 1988 (Boletín auriense. Anexos, 9).

García de Valdeavellano, Luis, Sobre los burgos y los burgueses de la España Medieval, Madrid, Real Academia de la Historia, 1960.

García Tato, Isidro, Las encomiendas gallegas de la Orden Militar de San Juan de Jerusalén. Estudio y Edición documental, vol. 1: Época Medieval, Santiago de Compostela, CSIC; Xunta de Galicia, Instituto de Estudios Gallegos "Padre Sarmiento", 2004.

Hermida Balado, Manuel, Monforte de Lemos, León, Ed. Everest S.A., 1987.

Iglesias Almeida, Ernesto, "Las fortificaciones monfortinas”, Cuadernos de Estudios Gallegos, XLVIII, fasc. 114 (2001), págs. 249-279. 
López Alsina, Fernando, "La repoblación humana costera del norte peninsular", en Los fueros de Ávilés y su época, Oviedo, Real Instituto de Estudios Asturianos, 2012.

López Alsina, Fernando, La ciudad de Santiago de Compostela en la Alta Edad Media, $2^{\mathrm{a}}$ ed. corregida, Santiago de Compostela, Consorcio de Santiago. Universidade de Santiago de Compostela, 2013.

López Peláez, Antolín, Los Benedictinos de Monforte, La Coruña, Ed. Carré, 1895.

López Pérez, María del Mar, Ferias y mercados en Castilla al final del Antiguo Régimen, tesis doctoral inédita dirigida por Tomás García-Cuenca Ariati, Madrid, Universidad Complutense de Madrid, Facultad de Geografía e Historia, 2004.

Lucas Álvarez, Manuel, El tumbo de San Julián de Samos (siglos VIII-XII), Estudio introductorio. Edición diplomática. Apéndices e índices, Santiago de Compostela, Obra Social Caixa Galicia, 1986.

Lucas Álvarez, Manuel, y Lucas Domínguez, Pedro, El priorato benedictino de San Vicenzo de Pombeiro y su colección diplomática en la Edad Media, Sada, Ediciós do Castro, 1996 (Galicia Medieval: Fontes, 2. Publicacións do Seminario de Estudos Galegos).

Monforte en imaxes. Un século de historia (1863-1963), León, Excmo. Concello de Monforte de Lemos; Evergráficas, 1991.

Moure-Mariño, Luis, Apuntes para la historia de Monforte de Lemos, Santiago de Compostela, Xunta de Galicia, 1997.

Pardo de Guevara y Valdés, Eduardo, Los Señores de Galicia. Tenentes y Condes de Lemos en la Edad Media, A Coruña, Fundación Pedro Barrié de la Maza, 2000 (Galicia histórica).

Portela Silva, María José (ed.), Documentos da Catedral de Lugo. Século XIV, Santiago de Compostela, Consello da Cultura Galega, Sección de Patrimonio, 2005 (Fontes para a Historia de Galicia, 5).

Risco, Manuel, España Sagrada: theatro geographico-historico de la Iglesia de España, origen, diuisiones y limites... antiguedad, traslaciones y estado... en todos los dominios de España, y Portugal, con varias disertaciones criticas... , Tomo XL, Madrid, 1796.

Rodríguez, Francisco Javier, Diccionario gallego-castellano, A Coruña, Ed. de Antonio de la Iglesia González, 1863. Recurso electrónico [en línea], disponible en $<$ http://sli.uvigo.es/ DdD/ddd_pescuda.phppescuda=regoa\&tipo_busca=lema> [Consulta: 21/06/2016].

Rodríguez Fernández, Carlos, La colección diplomática de San Vicente del Pino, tesis doctoral inédita dirigida por J.I. de Viana y Vieites, Granada, Universidad de Granada, Facultad de Filosofía y Letras, 1990.

Vázquez Sueiro, Germán, Historia de Monforte y su tierra de Lemos, Excmo. Ayto. de Monforte de Lemos, Ed. Evergráficas S.A., 1990. 